


\section{Pulmonary Emergencies}

Edited by

Leo Heunks, Alexandre Demoule and Wolfram Windisch

Editor in Chief

Robert Bals

This book is one in a series of ERS Monographs. Each individual issue provides a comprehensive overview of one specific clinical area of respiratory health, communicating information about the most advanced techniques and systems required for its investigation. It provides factual and useful scientific detail, drawing on specific case studies and looking into the diagnosis and management of individual patients. Previously published titles in this series are listed at the back of this Monograph.

ERS Monographs are available online at www.erspublications.com and print copies are available from www.ersbookshop.com

Purchased by ,

From: European Respiratory Society Publications (reader.ersjournals.com) 
Continuing medical education (CME) credits are available through many issues of the ERS Monograph. Following evaluation, successful Monographs are accredited by the European Board for Accreditation in Pneumology (EBAP) for 5 CME credits. To earn CME credits, read the book of your choice (it is clearly indicated on the online table of contents whether CME credits are available) then complete the CME question form that is available at www.erseducation.org/e-learning/cme-tests.aspx

Editorial Board: Antonio Anzueto (San Antonio, TX, USA), Leif Bjermer (Lund, Sweden), John R. Hurst (London, UK) and Carlos Robalo Cordeiro (Coimbra, Portugal).

Managing Editors: Rachel White and Catherine Pumphrey

European Respiratory Society, 442 Glossop Road, Sheffield, S10 2PX, UK

Tel: 441142672860 | E-mail: Monographdersj.org.uk

Published by European Respiratory Society (2016

December 2016

Print ISBN: 978-1-84984-073-6

Online ISBN: 978-1-84984-074-3

Print ISSN: $2312-508 \mathrm{X}$

Online ISSN: 2312-5098

Typesetting by Nova Techset Private Limited

Printed by Page Bros Ltd, Norwich, UK

All material is copyright to European Respiratory Society. It may not be reproduced in any way including electronic means without the express permission of the company.

Statements in the volume reflect the views of the authors, and not necessarily those of the European Respiratory Society, editors or publishers.
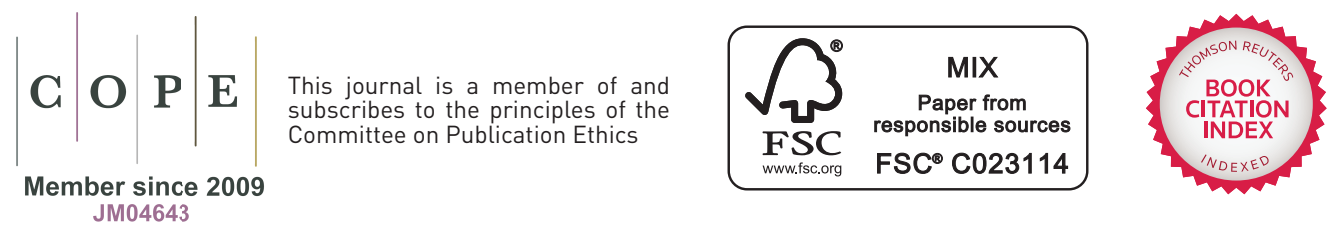

Purchased by , 


\section{Contents}

Pulmonary Emergencies

Preface

v

Guest Editors

vii

Introduction

$\mathbf{x}$

List of abbreviations

$x i$

\section{Clinical entities}

1. Pneumothorax

Steve Walker and Nick Maskell

2. Pulmonary embolism

Stefano Barco and Stavros V. Konstantinides

3. Right heart failure

Benjamin Sztrymf, Constance Vuillard, Athénaïs Boucly, Elise Artaud-Macari, Caroline Sattler, David Amar, Xavier Jaïs, Olivier Sitbon, Marc Humbert and Laurent Savale

4. Acute exacerbations of COPD

Alison Patricia Butler, Laura-Jane E. Smith and Alexander John Mackay

5. Acute exacerbations of asthma

Nirav R. Bhakta and Stephen C. Lazarus

6. Hypercapnic respiratory failure in non-COPD

Neeraj M. Shah and Patrick B. Murphy

7. Severe community-acquired pneumonia

Adamantia Liapikou, Catia Cilloniz, Adrian Ceccato and Antoni Torres

8. Acute exacerbations of interstitial lung disease

Marcel Veltkamp and Jan C. Grutters

9. Severe haemoptysis

Muriel Fartoukh, Guillaume Voiriot, Samuel Hadad, Hicham Masmoudi, Jalal Assouad, Marie-France Carette, Antoine Khalil and Antoine Parrot

Purchased by ,

From: European Respiratory Society Publications (reader.ersjournals.com) 
10. Foreign body aspiration and inhalation injury

Erik H.F.M. van der Heijden, Paul C. Fuchs and Jan-Philipp Stromps

11. Haematothorax

Erich Stoelben, Axel Gossmann and Servet Bölükbas

\section{Acute pulmonary interventions}

12. High-flow nasal cannula oxygen therapy

Rémi Coudroy, Jean-Pierre Frat and Arnaud W. Thille

Rosanna Vaschetto, Federico Longhini and Paolo Navalesi

14. Extracorporeal carbon dioxide removal

Christian Karagiannidis, Stefan Kluge, Stephan Strassmann and Wolfram Windisch

15. Acute bronchoscopy

Raffaele Scala

16. Chest tube insertion

Sanjay Adlakha, Mark Roberts and Nabeel Ali

Purchased by ,

From: European Respiratory Society Publications (reader.ersjournals.com) 


\title{
Preface
}

\author{
Robert Bals
}

Emergency situations in pulmonary medicine are critical for the patient and often stressful for the care providers. The most important factor in the successful management of such situations is to be prepared. Interruption of the function of the lung immediately results in an emergency situation. In the case of severe impairment of gas exchange, a catastrophic outcome will occur within a few minutes if adequate measures are not started. The management of respiratory acute situations is a core capability of respiratory and emergency medicine. Physicians in all areas of pulmonary medicine face critical situations daily. Maintaining the ability to manage emergencies adequately requires keeping knowledge up to date and training in critical procedures. In addition to the basic principles in this area, a number of new techniques and procedures have been developed in recent years. In contrast to the importance of this subject, there are only a few comprehensive textbooks available.

This ERS Monograph aims to provide the reader with a detailed overview of emergencies in pulmonary care, from a viewpoint close to the bedside. The book is split into two sections. The first section, on clinical entities, covers the most important emergency situations, while the second section, on acute pulmonary interventions, focuses on key techniques. This structure allows readers to learn systematically or to refresh their knowledge of the theory of pulmonary emergency management, including bedside interventions. Together with practical training and structural developments, this ERS Monograph will enable physicians and other healthcare providers to treat their patients safely in critical situations.

I would like to thank the Guest Editors, Leo Heunks, Alexandre Demoule and Wolfram Windisch, who have worked very successfully to select these topics and integrate them into a comprehensive book. I would also like to thank all the authors for their work. I am sure that this excellent ERS Monograph will 
be useful in clinical practice for a broad range of respiratory physicians and will help to improve the care of our patients.

Disclosures: R. Bals has received grants from the German Research Ministerium and the Deutsche Forschungsgemeinschaft. He has also received personal fees from GSK, AstraZeneca, Boehringer Ingelheim and CSL Behring.

Purchased by ,

From: European Respiratory Society Publications (reader.ersjournals.com) 


\section{Guest Editors}

\section{Leo Heunks}

Leo Heunks is professor of intensive care medicine at the VU University Medical Center Amsterdam (Amsterdam, the Netherlands). He received his undergraduate training and MD at the Radboud University (Nijmegen, the Netherlands). From 1996 to 2000, he was a PhD student in respiratory physiology. During the $\mathrm{PhD}$ programme he visited the Mayo Clinic (Rochester, MN, USA) for 7 months to study skeletal muscle single fibre mechanics and intracellular calcium imaging (with mentor Gary Sieck). He trained as a pulmonologist at the Radboud University Medical Center from 2000 to 2006, followed by a 2 -year fellowship in intensive care medicine, and became consultant in intensive care at the same hospital. He was co-founder of the first specialised ventilator-weaning unit in the Netherlands and chair of the Dutch guideline for difficult weaning. In 2016, he moved to the VU University Medical Center Amsterdam, Dept of Intensive Care.

His research interests include effects of critical illness on respiratory muscle function, mechanical ventilation, weaning from the ventilator and ARDS. He has spent research fellowships at Loyola University Medical Center (Chicago, IL, USA) and St Michael's Hospital, Toronto (ON, Canada). In both clinical work and research, he promotes the understanding of physiological principles. Only when we are willing to understand the underlying physiology can we conduct meaningful research and optimal patient care.

Currently, Leo Heunks is secretary of European Respiratory Society assembly 2 (respiratory intensive care). 


\section{Alexandre Demoule}

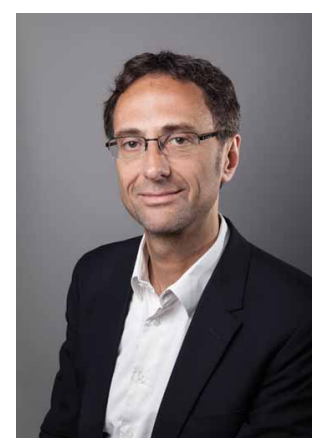

Alexandre Demoule is professor of intensive care medicine at the Pierre and Marie Curie University Medical Centre in Paris (France). He is the director of the medical ICU, the step-down unit and the weaning centre within the Dept of Pneumology and Intensive Care Medicine, La Pitié-Salpêtrière hospital in Paris. He was trained in pneumology and physiology at the Pierre and Marie Curie University under the supervision of Thomas Similowski and in intensive care medicine at Paris-Est University in Créteil, where he was also a research fellow (2001-2002) in mechanical ventilation with Laurent Brochard. From 2003 to 2006, he was a $\mathrm{PhD}$ student in respiratory physiology at the Pierre and Marie Curie University. During the PhD programme he spent 1.5 years at the Meakins-Christie Laboratories, McGill University (Montreal, QC, Canada), under the supervision of Basil Petrof.

His main research field is patient-ventilator interactions. It involves specific research topics such as brain-ventilator interactions, the impact of mechanical ventilation on respiratory sensations and comfort, and respiratory muscle dysfunction in mechanically ventilated patients. He also conducts clinical studies on noninvasive mechanical ventilation in acute respiratory failure and on new modes of mechanical ventilation. His research projects are conducted within UMR_S 1158, a joint research unit between Pierre and Marie Curie University and the French National Institute of Health and Medical Research (Inserm).

Alexandre Demoule is the chair of the annual meeting of the French Intensive Care Society. He has organised several conferences on mechanical ventilation, is co-author of guidelines in the field of intensive care medicine and serves as an invited speaker at international conferences.

\section{Wolfram Windisch}

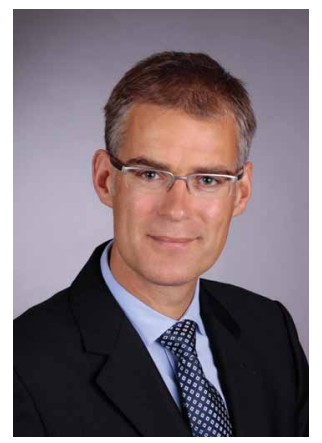

Wolfram Windisch is the medical director of the Dept of Pneumology and Critical Care Medicine, Clinic of Cologne (Cologne, Germany), and holds the professorial chair for Pneumology at the University of Witten/Herdecke (Cologne). His department is specifically dedicated to the acute and chronic treatment of respiratory failure, invasive and noninvasive mechanical ventilation, extracorporeal lung assist, weaning from mechanical ventilation and sleep medicine. In addition, his other main focuses are COPD/asthma, thoracic oncology, interstitial lung diseases, infectious diseases and cystic fibrosis. His research interests include respiratory physiology, all aspects of mechanical ventilation, monitoring of respiratory function in the acute and 
chronic setting, and health-related quality of life in patients with severe chronic respiratory failure.

In addition, Wolfram Windisch has chaired the German Interdisciplinary Society of Home Mechanical Ventilation, the group for noninvasive ventilatory support within assembly 2 of the European Respiratory Society, and the section for intensive care medicine of the German Society of Pneumology and Ventilation. He has organised several symposia and conferences on mechanical ventilation and serves as an invited speaker at national and international conferences. $\mathrm{He}$ also serves as the responsible author for the German guidelines for noninvasive and invasive mechanical ventilation for treatment of chronic respiratory failure, and has served as a co-author for the German guidelines on acute NIV and for the German guidelines on prolonged weaning. 


\title{
ERS | monograph
}

\section{Introduction}

\author{
Leo Heunks ${ }^{1}$, Alexandre Demoule ${ }^{2,3}$ and Wolfram Windisch ${ }^{4}$
}

Pulmonary emergencies are potentially life-threatening conditions that require immediate attention to avoid delay in treatment. These patients most often present with severe dyspnoea, but other symptoms and signs may include collapse, chest pain and haemoptysis. A variety of healthcare professionals, such as pulmonologists, emergency room (ER) physicians, intensivists, general internists, anaesthesiologists, respiratory therapists, residents and ER nurses, may be involved in the acute care of these patients. The differential diagnosis of a pulmonary emergency, e.g. presenting with dyspnoea, may be very broad and could result from dysfunction of the airways, lung parenchyma or pulmonary vasculature. In every patient presenting to the ER, this differential diagnosis should be considered.

In this ERS Monograph, the most common and also rather less common causes for pulmonary emergencies are described. Each chapter discusses pathophysiology, differential diagnosis and treatment strategies. In addition, the last five chapters describe common pulmonary interventions in detail. The chapters are written by recognised experts in their field and all chapters have been peer reviewed. Thanks to the effort of so many professionals, this has become a very impressive ERS Monograph that will definitely be of value to all colleagues involved in the care of patients with pulmonary emergencies.

We would like to thank all the authors, reviewers and ERS staff for their time and effort to make this ERS Monograph a success.

\footnotetext{
Disclosures: L. Heunks has received research grants from Orion Pharma and Bayer, and personal fees from Biomarin, Maquet and Orion Pharma. A. Demoule has received grants from Maquet, Covidien and Philips, personal fees from Maquet, Covidien and Merck Sharp \& Dohme, and nonfinancial support from Philips and Dräger, and also has financial relationships with ResMed and Fisher \& Paykel. W. Windisch has received fees for advisory board meetings and lectures, and an open research grant for Cologne-Merheim Hospital from Maquet Cardiopulmonary.
}

\footnotetext{
${ }^{1}$ Dept of Intensive Care Medicine, VU University Medical Center Amsterdam, Amsterdam, The Netherlands. ${ }^{2}$ Sorbonne Universités, UPMC Univ Paris 06, INSERM, UMRS1158 Neurophysiologie respiratoire expérimentale et clinique, Paris, France. ${ }^{3}$ AP-HP, Groupe Hospitalier Pitié-Salpêtrière Charles Foix, Service de Pneumologie et Réanimation Médicale (Département "R3S"), Paris, France. ${ }^{4}$ Dept of Pneumology and Critical Care Medicine, Cologne-Merheim Hospital, ARDS and ECMO Centre, Kliniken der Stadt Köln gGmbH, Witten/Herdecke University Hospital, Cologne, Germany.
}

Correspondence: Leo Heunks, VU University Medical Center Amsterdam, Dept of Intensive Care Medicine, P.O. Box 7057, 1007 MB, Amsterdam, The Netherlands. E-mail: L.Heunks@VUmc.nl

Copyright @ERS 2016. Print ISBN: 978-1-84984-073-6. Online ISBN: 978-1-84984-074-3. Print ISSN: 2312-508X. Online ISSN: $2312-5098$.

Purchased by , 


\section{List of abbreviations}

$\begin{array}{ll}\text { ARDS } & \text { acute respiratory distress syndrome } \\ \mathrm{BAL} & \text { bronchoalveolar lavage } \\ \mathrm{BMI} & \text { body mass index } \\ \mathrm{COPD} & \text { chronic obstructive pulmonary disease } \\ \mathrm{CPAP} & \text { continuous positive airway pressure } \\ \mathrm{CT} & \text { computed tomography } \\ \mathrm{ECMO} & \text { extracorporeal membrane oxygenation } \\ \mathrm{FEV} 1 & \text { forced expiratory volume in first second } \\ \mathrm{FIO} & \text { inspiratory oxygen fraction } \\ \mathrm{ICU} & \text { intensive care unit } \\ \mathrm{NIV} & \text { noninvasive ventilation } \\ \mathrm{PaCO}_{2} & \text { arterial carbon dioxide tension } \\ \mathrm{PaO}_{2} & \text { arterial oxygen tension } \\ \mathrm{PEEP} & \text { positive end-expiratory pressure } \\ \mathrm{RCT} & \text { randomised controlled trial } \\ \mathrm{SpO}_{2} & \text { arterial oxygen saturation measured by pulse oximetry }\end{array}$

